\title{
Preparing for the MeCCSA-PGN Conference: Reflections from the Organising Committee
}

\author{
PAWAS BISHT, ALENA PFOSER \& PAULINE VAN ROMONDT VIS, Loughborough \\ University
}

Preparing for the 2012 MeCCSA-PGN conference in the Department of Social Sciences at Loughborough University has been an exciting project of collaborative work and learning for the organising committee. At the time of writing, the event is still two months away and we are in the midst of the preparations, and what follows is a reflection on our experience which we hope might be of some use for those organising future editions of the conference. We will be indicating both the difficulties we've encountered and the practices that worked well.

\section{A team that works together}

While we secured rights to host the conference in 2010, preparations began in earnest in early 2011. A well functioning organising team is essential to the success of any event. In our case, the core organising committee is made up of $9 \mathrm{PhD}$ students in the $2^{\text {nd }}$ and $3^{\text {rd }}$ year of study. While some of us were part of the group that prepared the bid document, others were inducted after we had secured the conference. In our experience, having representation from across different years of study has been useful both in ensuring a variety of perspectives on planning issues and in managing organisational workload. One of the first things we did after coming together as a committee was to demarcate the different organisational tasks and have a clear separation of responsibilities: registration, programme, finances, catering and accommodation, website, social events and overall coordination. This demarcation of responsibilities has not only ensured that all members have a clear sense of the tasks assigned to them but also prevented any ill feeling in terms of any one person feeling overburdened. Each person developed a time line of "things to do" until the conference; this helped get a concrete sense of the workload and allowed for the coordination of different tasks (for example, the person coordinating registration relied on information linked to accommodation and the conference programme). We also shared some tasks such as reviewing the abstracts received and developing the thematic panels for the presentations. This, coupled with regular meetings, has ensured that the team retains a collective ownership of the event. Working together has given us a sense that organising a relatively big event like a conference is not only manageable but also enjoyable - it has been a very positive group experience and has contributed to improved interaction between $\mathrm{PhD}$ students in the department. 
Volume 5, Issue 2

September 2012

\section{Institutional support}

The departmental staff lent us their support from the very beginning when we submitted the bid to host the conference. Since then, we've made sure that the relevant people in the department (in our case, the post-graduate research coordinator and the head of department) were kept up to date with our preparations. This allowed us to seek their help at key moments when we came up against problems in securing venues and in setting up the financial accounts for the conference. In our experience, having the weight of the department behind you when making requests for facilities at the university level was critical for speedy processing and successful results.

Beyond this, keeping the academics informed of our preparations also made it easier for us to seek their participation in the plenary sessions being planned for the conference. We've thus been able to draw on the range of world leading research expertise within the department to offer a diversity of keynotes and workshops to the conference participants. Other academic and research staff will also be chairing some of the panel presentations. In our view, drawing on the research strengths of the host institution when planning plenary events, workshops and other events is a great way of enriching the conference. On the one hand, it ensures the active participation of the academic staff in the PGR event and on the other allows the visiting delegates to benefit from the full range of expertise that the host institution has to offer.

\section{Scheduling problems}

The main problem we encountered in the organisation of the Loughborough event was in finding suitable dates. This problem emerged because of the special (and unforeseen) circumstance of Loughborough University being chosen as the official preparation camp for the British and Japanese Olympic teams. In view of the strain on university resources and the security arrangements, the administration postponed all university events (including graduation ceremonies and conferences) scheduled in the period between $10^{\text {th }}$ June and $10^{\text {th }}$ August. This prevented us from having the conference at its usual time (mid June-July). In consultation with the MeCCSA-PGN committee, the conference had to be rescheduled in September; the shift in dates meant that we had to completely reconfigure our preparation timelines and rearrange key details such as the conference venue. The key lesson to be derived from this experience is that organisers should attempt to foresee any difficulties that might arise in scheduling the event and if possible, have alternative arrangements in place. Do consult the wider university administration, beyond your department, when scheduling the event and avoid any unpleasant surprises. When such situations do arise, despite your best efforts, seek support at the departmental level. As in our case, it is quite likely that the academic staff will have come across the same set of difficulties themselves and might be better positioned to propose solutions.

Beyond the problems, the experience of planning and organising the conference has been deeply satisfying for all of us in the organising team. If you have any questions or would like 
Networking Knowledge

Volume 5, Issue 2

September 2012

to get in touch, email us at Meccsapgn2012@lboro.ac.uk.

The Loughborough conference organizing committee includes Sarah Lewis, David Smith, Dana Nassif, Pawas Bisht, Pauline van Romondt Vis, Alena Pfoser, Laura Ranca, Alessandro Froldi and Georgie Payne. 